\title{
Hyperfibrinogenemia in Rats Treated with Meloxicam
}

\author{
Mónica Moya, ${ }^{1} \mathrm{PhD}$, Vilma CAmpana, ${ }^{1} \mathrm{PhD}$, Antonio Gavotto, ${ }^{1} \mathrm{PhD}$, \\ L Spitale, ${ }^{2} \mathrm{PhD}$, Juan Simes, ${ }^{1} \mathrm{PhD}$, and José Palma, ${ }^{1} \mathrm{PhD}$
}

\begin{abstract}
SUMMARY
Fibrinogen secretion is mediated by prostaglandin biosynthesis and is considered a risk factor for cardiovascular disease. Since meloxicam produces inhibition of prostaglandin biosynthesis it may help to normalize hyperfibrinogenemia.

We investigated the pharmacological effect of meloxicam on fibrinogen levels and the possible regression of histopathological lesions of thoracic aorta. Rats were subjected to multiple injuries (MI) in the form of laparotomies (Lx) during a 30 day period (1/week). Meloxicam $0.065 \mathrm{mg} / \mathrm{kg} /$ day (per rat) was administered orally immediately after the third Lx in multiple injury animals during a ten day period. Blood was obtained 72 hours after the last injury in all groups. Fibrinogen was measured by spectrophotometry and the values were expressed in $\mathrm{mg} / \mathrm{dL}$. A statistically significant increment of fibrinogen was

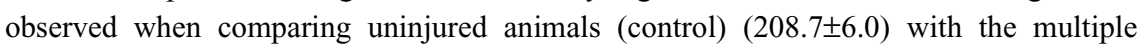
injury group (336.6 \pm 7.5$)(P<0.001)$. Fibrinogen decreased to the control value in the meloxicam group (198 \pm 8.7 ). Histopathological lesions were similar in the MI and meloxicam groups, showing endothelial denudation and intima enlargement from the thoracic aorta in $96 \%$ of the slices studied. The decrease in fibrinogen in the meloxicam group would be due to cyclooxygenase-2 (Cox-2) selective inhibition, even though the histopathological lesions did not regress. (Jpn Heart J 2002; 43: 559-566)
\end{abstract}

Key words: Fibrinogen, Vascular disease, NSAIDs, Endothelial dysfunction, Meloxicam, Endothelial denudation

THERE is epidemiological evidence which shows that, through fibrinogen, the hemostatic system plays an important role in the pathogenesis of vascular disease. ${ }^{1)}$ Recently, the Atherosclerosis Risk in Community Study (ARIC study) has confirmed the involement of fibrinogen as a cardiovascular risk factor. ${ }^{2)}$

One of the hypotheses used to explain the genesis of atherosclerosis is that proposed by Ross, ${ }^{3)}$ which implies endothelial alteration as a response to vascular lesions to which certain risk factors may contribute, including hypercholesterolemia, hypertension, smoking, increased fibrinogen, increased low density lipo-

\footnotetext{
From ${ }^{1}$ Cátedra de Física Biomédica, Facultad de Ciencias Medicas, Universidad Nacional de Córdoba, ${ }^{2}$ Cátedra de Anatomía Patológica, Santa Rosa, Argentina.

Address for correspondence; Menica Moya, MD, Facultad de Ciencias Medicas, Universidad Nacional de Cordoba. Santa Rosa 1085. (5000) Argentina. Supported by Grants n 194/2000 from Secretary of Cience and Tecnology (SECy T) from University of Cordoba. Republica Argentina.

Received for publication Octorber 15, 2001.

Revised and accepted April 11, 2002.
} 
proteins (LDL), hyperinsulinism, and obesity. Such factors would generate an imbalance in the endothelial hemostatic balance, and this would activate a rapid and transitory induction of procoagulant reactions in the endothelium and the suppression of anticoagulant activity. This, in turn, would favor the development and maintenance of intravascular fibrin, contributing to the localization, assembling, and activation of several coagulation factors. ${ }^{4)}$

Endothelial Dysfunction could activate several coagulation factors. Intact endothelial cells have little or none tissue factors activity, but an injury produced by different cardiovascular risk factors, line an fibrinogen, would increased the tissue factor expression. As a consequence of cytokine activation the endothelial cell surface acqire procoagulant properties.

When the cellular membrane is activated by a stimulus, arachidonic acid is synthesized, generating oxygenated products through the action of different enzymes such as cyclooxygenase $\left(\mathrm{C}_{\mathrm{OX}}\right)$ and lipooxygenase. Previous studies have shown that induced tissue injury causes the synthesis of chemical factor mediators such as prostacyclins, thromboxanes, and prostaglandins in an inflammatory response by cyclooxygenase activation. ${ }^{6}$ Among the most stable is prostaglandin $\mathrm{E}_{2}$, which maintains an inflammatory focus and mediates plasmatic fibrinogen synthesis. ${ }^{7)}$ Moreover, the plasma variations of the inflammatory markers (e.g, fibrinogen) could be related to the anatomopathological lesions of an acute inflammatory focus.

Taking into account the Cox-2/Cox-1 inhibiting profile from different nonsteroidal anti-inflammatory drugs (NSAIDS), meloxicam could help normalize hyperfibrinogenemia, ${ }^{8}$ since it is a Cox-2 selective inhibitor.

In spite of all the above mentioned studies, the importance of hyperfibrinogenemia in ischemic cardiovascular disease is not yet clear, ${ }^{9)}$ and neither is which drug or drugs could be used to control hyperfibrinogenemia. The objective of the present work was therefore to study the involvement of hyperfibrinogenemia in producing aortic anatomopathological changes and its possible regression with meloxicam treatment.

\section{Methods ANd MATERIALS}

Male Suquía strain rats, $280 \pm 20 \mathrm{~g}$ average weight, were divided into the following three groups (n: 18) control (a), multiple injury in 30 days (one laparotomy per week)(b) and multiple injury in 30 days + meloxicam (c).

After anesthesia by ether inhalation, the surgical injury was induced by laparotomies (Lx) (media and paralateral anterior), an approximate $4 \mathrm{~cm}$ long caudal incision in the skin was made followed by an incision over the abdominal muscles. Meloxicam was injected intramuscularly at a daily dose of $0.065 \mathrm{mg} / \mathrm{kg}$ 
(equivalent to $0.05 \mathrm{~mL}$ ) into each rat immediately after the third operation and for a 10 day period. ${ }^{10)}$

All different groups previous to ether anethesia inhalation, were exsanguinated 72 hours after the last surgery. Fibrinogen was determined by the method of Ratnoff and Menzie. ${ }^{11)}$ The results are expressed in $\mathrm{mg} / \mathrm{dL}$ and were obtained using a Metrolab 1700 Spectrophotometer (Buenos Aires, Argentina).

The thoracic aorta of each animal was cut from the origin to the end, fixed in buffered $10 \%$ formalin, embedded in paraffin, and then the histological slices were stained with hematoxylin-eosin. Thirty slices of $4 \mu \mathrm{m}$ thickness were prepased by cross-slicing every $1 \mathrm{~mm}$. A total of 300 slices per group were studied and quantification of the lesions was made in a blinded manner and examined using low, middle and high power light microscopy. All of the slices obtained were examined with a $10 \mathrm{X}$ objective.

A variance analysis linear model (Levene test) and normality analysis (Shapiro-Wiks test) were used to test the results of the plasm a fibrinogen concentrations. The Ryan-Einot-Gabriel-Welsch multiple ranks test was used to compare all of the possible media pair combinations. The histopathology results were analyzed by the chi square test. A value of $P<0.05$ was regarded as significant.

\section{RESUlts}

The effects of meloxicam on fibrinogen concentration are shown in Figure 1.

A significant increase in the fibrinogen concentration was observed in the 30 day multiple injury group (336.6 \pm 7.5$)$ compared to the control group (207.0 $\pm 3.0)(P<0.001)$ (Figure 2.).

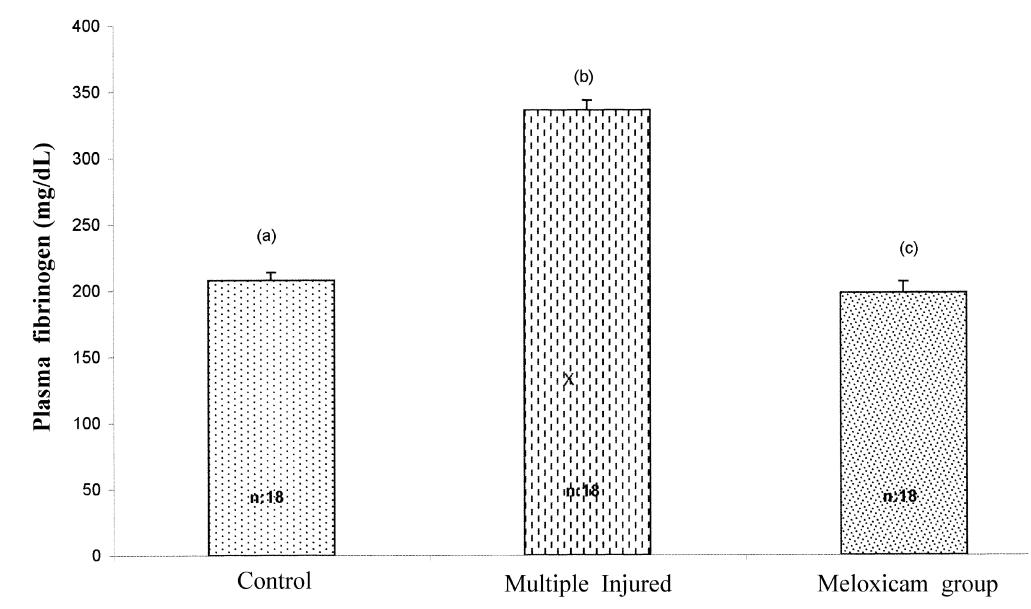

Figure 1. Effect of meloxicam on fibrinogen concentrations in multiple-injury rats. $\mathrm{X} \pm \mathrm{SE}$ (a) vs (b): $P<0.001$ : (b) vs (c): $P<0.001$; (a) vs (c): N.S 
On the contrary, no significant differences were observed when the meloxicam group was compared to controls (no injury), since the plasma fibrinogen levels decreased to control values.

The histopathological evaluations are shown in the Table. No microscopic changes in any of the layers of the thoracic aorta were observed in the control group (Figure 2.). Out of a total number of 540 anatomopathological slices, endothelial denudation and intima widening were observed in $486(90 \%)$ in the

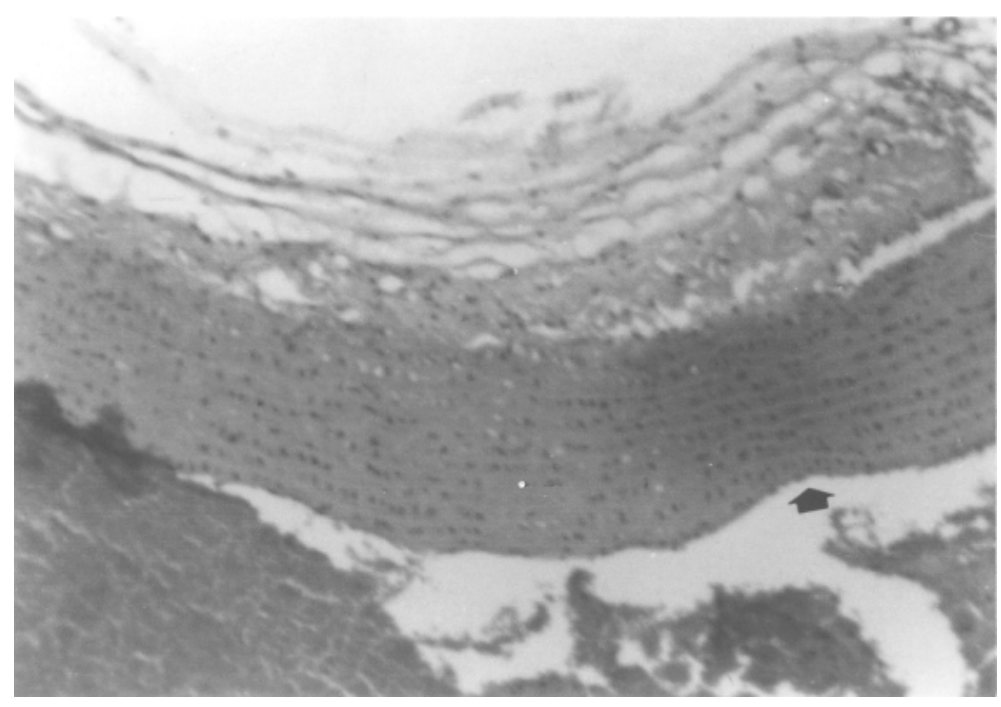

Figure 2. Microscopic view of thoracic aorta from control rat, that showed a normal wall structure (arrow). (H-E X 40)

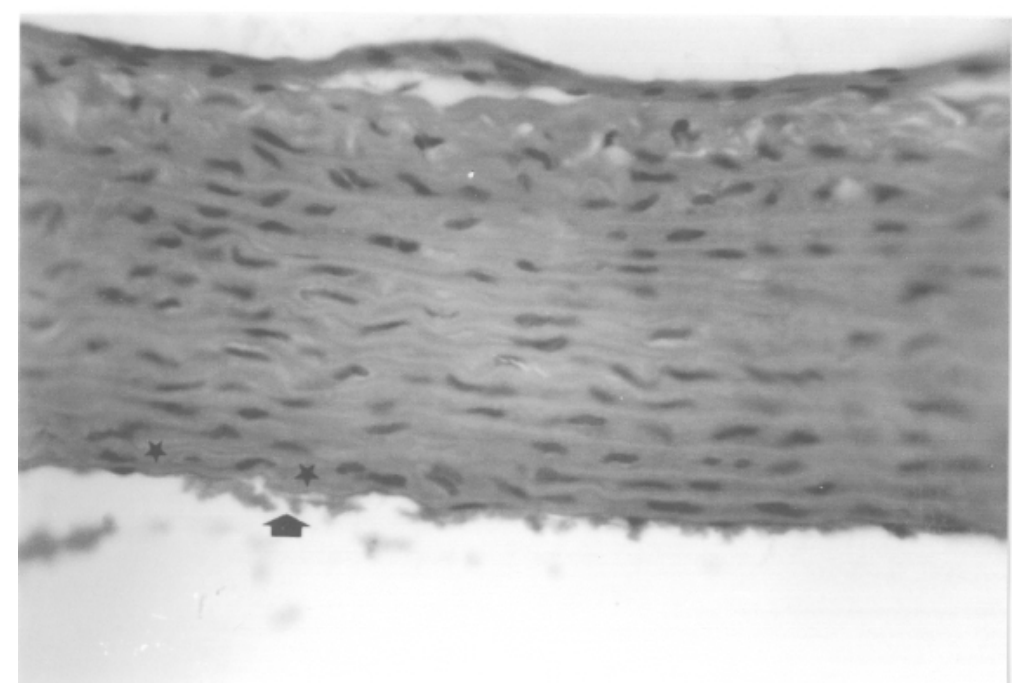

Figure 3. Microscopic view of thoracic aorta from multiple injury group rat that showed endothelial denudation areas (arrow), enlarged intima (star), and moderate disruption of internal elastic layer (H-E X 10). 
30 day multiple-injury group (Figure 3.). A statistically significant difference in the lesions was observed in the MI group compared with the control group (1.5\%) $(P<0.006)$. On the contrary, in the meloxicam group (Figure 4), the histopathological lesions persisted in 478 (89\%), indicating there was no statistically significant difference compared to the MI group without treatment.

Table. Histopathological Lesions in Thoracic Aorta of Rats Subjected to Multiple Injuries and Rats Treated with Meloxican

\begin{tabular}{lcc}
\hline Group & $\begin{array}{c}\text { Endothelial } \\
\text { denudation }\end{array}$ & $\begin{array}{c}\text { Lesion in other } \\
\text { layers }\end{array}$ \\
\hline Multiple injury (b) & $486^{*}$ & $330^{*}$ \\
Meloxicam (c) & $478^{*}$ & $314^{*}$ \\
\hline
\end{tabular}

* Number of histopathological slices. Endothelial denudation: $b$ vs c: NS. Lesion in other layers: b vs c: NS.

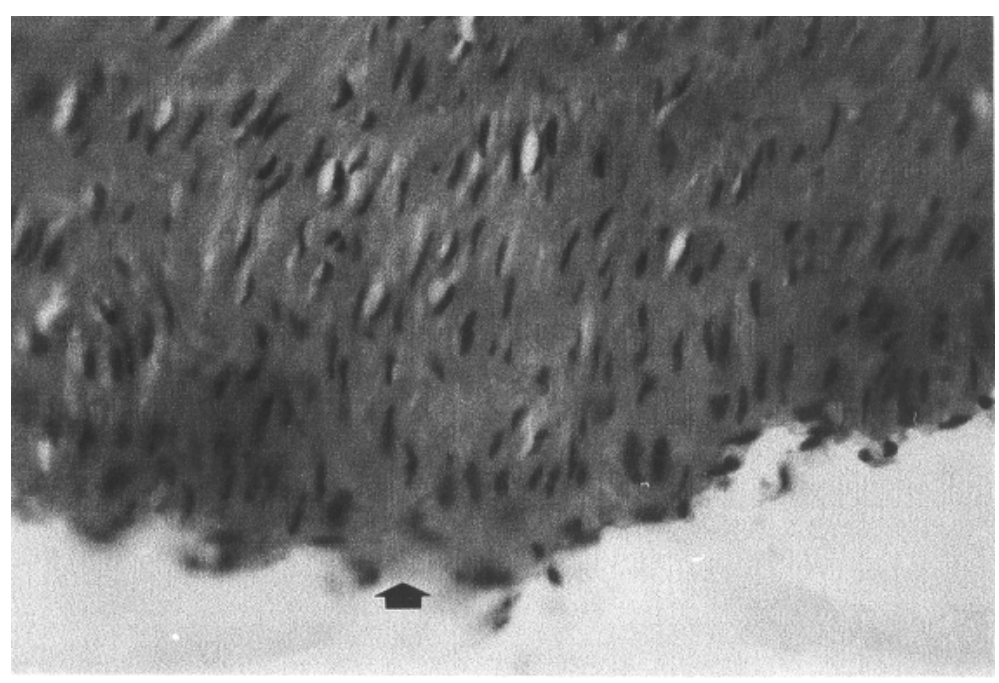

Figure 4. Microscopic view of thoracic aorta from meloxicam group rat that exhibited lesions similar to those in multiple injury group (arrow) (H-E X 10). 


\section{DiscuSSION}

The highest peak in fibrinogen increase is resistered between 24 and 48 hours after tissue injury and occurs by adrenal and extra adrenal pathway, these values remain high for 6 days and then slowly start to normalize before reaching normal basal values after 8 or 9 days. ${ }^{12)}$ In the multiple injury group, the increased values remained significant due to the persistence of the stimulus that would produce an inflammatory induction whose response consists of liver stimulation for the synthesis and subsequent release of acute phase reactants, among which fibrinogen is one. ${ }^{13)}$

Considering that fibrinogen acts as a cardiovascular risk factor and could cause and contribute to the progression or complication of ischemic disease, ${ }^{14)}$ in our results, we observed that significant fibrinogen increases during the 8 days after injury are not accompanied by histopathological lesions. Perhaps hyperfibrinogenemia persists longer or is associated with other risk factors to produce lesions in such a short period.

Moreover, when the anatomopathological lesions of the multiple-injury group (30 days) are analyzed, the predominant type of lesion is endothelial denudation corresponding to Type II of the Stary classification. ${ }^{15)}$ The presence of endothelial denudation in the vessel wall leaves the underlying collagen exposed, thus facilitating, platelet aggregation and progression of the vascular disease. ${ }^{16}$ ) Fibrinogen could participate in the initial changes that originate in the atherosclerotic vascular disease at the endothelial level, since this most likely, together with thrombin and fibrinogen degradation products, may contribute to the injury due to their chemotactic and mitogenic properties. In addition, the increased fibrinogen concentration may represent initial endothelial dysfunction, which is an essential condition for atherogenesis. ${ }^{17)}$

The administration of meloxicam to animals with multiple injuries produced a decrease in fibrinogen to control values due to the preferential inhibition of the Cox-2 inducible isoform. As already known, Cox has a key role in the conversion of the arachidonic acid in prostaglandins through the Cox pathway. The pathway can be activated by a physiological stimulus that produces constitutive Cox-1. Prostaglandins are involved in certain physiological functions, such as platelet stability by means of the synthesis of thromboxane $\mathrm{A}_{2}$, and the synthesis of prostacyclins that protect the endothelium gastric mucosa and the kidney. The pathway can also be activated by an inflammatory stimulus that originates in activated macrophages and other cells inducing Cox-2 production. The latter, in turn, produces proteases, prostaglandins, and other inflammatory mediators responsible for the pro-inflammatory and inflammatory effects. ${ }^{18)}$ However, since meloxicam inhibits Cox-2 preferentially, it produces a reduction in prostaglandin biosynthe- 
sis, and since the prostaglandin $\mathrm{E}_{2}$ pathway is one of the mechanisms that mediates the synthesis and secretion of fibrinogen, the latter would also decrease its concentrations. In addition, since it is known that Cox-2 is induced in migratory and other cells through inflammatory stimuli and cytokines, meloxicam would also block the release of cytokines involved in the process. Since fibrinogen also uses this route to increase its production, the basal levels observed in animals treated with this drug could also be due to this cause. ${ }^{19)}$ In previous work by our laboratory, we studied the effects of indomethacin and diclofenac in injured rats, both NSAIDS that preferentially inhibit Cox-1. They produced an effect on fibrinogen levels similar to that of meloxicam..$^{20,21)}$

However, meloxicam may have another advantage, that is since it is a Cox2 preferential inhibitor, it would not block constitutive Cox-1 which is responsible for mediating prostacyclin $\left(\mathrm{PGI}_{2}\right)$ production at the endothelial level. The endothelium synthesizes $\mathrm{PGI}_{2}$, which is a potent inhibitor of platelet adhesiveness and also intervenes actively in several natural anticoagulant systems such as heparin and the formation of antithrombin, protein $\mathrm{C}$, and the production of thrombomodulin and plasminogen tissue activator. These substances help maintain anticoagulant function at the endothelial level. ${ }^{22}$ Obviously, it is very important to keep this function in this endothelial dysfunction situation caused by hyperfibrinogenemia, since endothelial activation is characterized by an imbalance between anticoagulant and procoagulant mechanisms. Nevertheless, in spite of the positive effects of meloxicam on the fibrinogen increase, no histopathological lesion regressions at the vascular wall level were observed. This might be due to the fact that the administration time was short or that the action of meloxicam only interfered in some of the many ways that produce fibrinogen. In addition, we have also investigated the effect of celecoxib on plasma fibrinogen levels in 30 day multiple injury rats and found it was similar to that of meloxicam (unpublished data).

From the preventive and clinical medicine point of view, it would be beneficial to determine what drug could be used to counteract the effects of fibrinogen in people presenting this modified factor.

\section{REFERENCES}

1. Smith EB, Thompson WD. Fibrinogen as a factor in atherogenesis. Thromb Res 1994; 71: 1-19.

2. Folsom AR, Kenneth $\mathrm{K} \mathrm{Wu}$, Wayne $\mathrm{D}$, et al. Prospective study of hemostatic factors and incidence of coronary heart disease. Circulation. 1997; 96: 1102-8.

3. Ross R. Mechanisms of disease: atherosclerosis- an inflammatory disease. N Engl J Med 1999; 340: 115-26.

4. Panza JA, Cannon RO (eds). Endothelium, nitric oxide, and atherosclerosis. New York, Future Publishing Co, 1999. 
5. Nawroth PP, MacCarthy D, Kisiel W, Handley D, Stern DM. Cellular processing of bovine factors X and Xa by cultured bovine aortic endothelial cells. J Exp Med 1995; 162.

6. Pairet M, Engelhardt G. The physiological and therapeutic significance of distinct isoforms (PGHS-1 and PGHS-2) of prostaglandin H synthase. Fund \& Clin Pharm 1996; 10: 1-15.

7. Gavotto A. \& Palma JA. Role of histamine on plasma fibrinogen levels in rats with (laparotomy). Arch Int Physiol Biochem 1985; 93: 175-9.

8. Engelhardt G. Pharmacology of Meloxicam, a new non-steroidal anti-inflammatory drug with an improved safety profile through preferential inhibition of Cox-2. British J Rheum, 1996; 35: 4-12.

9. Ceriello A, Pirisi M, Giacomello R, et al. Fibrinogen plasma levels as a marker of thrombin activation: New insights on the role of fibrinogen as a cardiovascular factor. Thromb \& Hemost 1999; 71: 593-5.

10. Engelhardt G, Homma D, Schnitzer CHr. Meloxicam: a potent inhibitor or adjuvant arthritis in the Lewis rat. Inflam Res 1995; 44 :548-55.

11. Ratnoff OD, Menzie AC. A method for the determination of fibrinogen in small samples of plasma. J. Lab. Clin. Med 1957; 37: 316-20.

12. Gavotto AC, Palma JA, Villagra de Lacuara SB. Interaction of prostaglandin $\mathrm{E}_{1}$, bradykinin and histamine and the increase of plasma fibrinogen in rats. Prostaglandins 1985; 30: 879-86.

13. Guadiz G, Sporn LA, Simpsons Haidaris P. Thrombin cleavage independent deposition of fibrinogen in extracellular matrices. Blood 1997; 90: 2644-53.

14. Razaahmad A. Fibrinogen a diagnostic marker for early ischemic. Biotech \& Histochem 1994; 69: 268-72.

15. Stary HC, Chandler AB, Glagov S, Guyton JR, et al. A definition of initial, fatty streak and intermediate lesions of atherosclerosis. A report from the Committee on Vascular Lesions of the Council of Atherosclerosis. American Heart Association. Circulation 1994, 89: 2462.

16. Segrest JP, Anantharamaiah GM. Pathogenesis of atherosclerosis. Curr Opin Cardiol 1999; 9: 404-10.

17. Chordá C, Páramo JA. Endotelio vascular: fisiopatología y participación en la trombogénesis. Sangre 1995; 40 : 491-8.

18. Vane JR. Mechanism of action of NSAID. British J Rheum 1996; 35 (Supl.1): 1-3

19. Lowry SF. Cytokines: mediators of immunity and inflammation. Arch Surg 1993; 1235-41.

20. Gavotto AC, Palma JA and Villagra B. Effects of indomethacin on plasma fibrinogen levels in rats with tissue injury. Arch Int Pharmacodyn 1985; 274: 320-7.

21. Campana V, Moya M, Gavotto A, Juri H and Palma J. Effects of diclofenac sodium and He-Ne laser irradiation on plasmatic fibrinogen. J Clin Laser Med \& Surg 1998; 16: 317-20.

22. Vane JR, Anggard EE, Botín RM. Regulatory functions of the vascular endothelium. N Engl J Med 1990: 3237. 